\title{
Surface expression of NMDA receptor changes during memory consolidation in the crab Neohelice granulata
}

\author{
Yanil Hepp, ${ }^{1,2}$ Angeles Salles, ${ }^{1,2}$ Martin Carbo-Tano, ${ }^{1}$ Maria Eugenia Pedreira, ${ }^{1}$ \\ and Ramiro Freudenthal ${ }^{1}$ \\ ${ }^{1}$ Laboratorio de Neurobiología de la Memoria, Facultad de Ciencias Exactas y Naturales, Departamento de Fisiología y Biología \\ Molecular y Celular, Universidad de Buenos Aires, IFIBYNE, CONICET. Pab. II, $2^{\circ}$ piso, Int. Güiraldes 2160, CP 1428, Ciudad \\ Universitaria, Ciudad Autónoma de Buenos Aires, Argentina
}

\begin{abstract}
The aim of the present study was to analyze the surface expression of the NMDA-like receptors during the consolidation of contextual learning in the crab Neohelice granulata. Memory storage is based on alterations in the strength of synaptic connections between neurons. The glutamatergic synapses undergo various forms of $\mathrm{N}$-methyl-D aspartate receptor (NMDAR)dependent changes in strength, a process that affects the abundance of other receptors at the synapse and underlies some forms of learning and memory. Here we propose a direct regulation of the NMDAR. Changes in NMDAR's functionality might be induced by the modification of the subunit's expression or cellular trafficking. This trafficking does not only include NMDAR's movement between synaptic and extra-synaptic localizations but also the cycling between intracellular compartments and the plasma membrane, a process called surface expression. Consolidation of contextual learning affects the surface expression of the receptor without affecting its general expression. The surface expression of the GluNl subunit of the NMDAR is down-regulated immediately after training, up-regulated $3 \mathrm{~h}$ after training and returns to naïve and control levels $24 \mathrm{~h}$ after training. The changes in NMDAR surface expression observed in the central brain are not seen in the thoracic ganglion. A similar increment in surface expression of GluN1 in the central brain is observed $3 \mathrm{~h}$ after administration of the competitive $\mathrm{GABA}_{\mathrm{A}}$ receptor antagonist, bicuculline. These consolidation changes are part of a plasticity event that first, during the down-regulation, stabilizes the trace and later, at 3-h post-training, changes the threshold for synapse activation.
\end{abstract}

It is generally accepted that the storage of memory is based on alterations in the strength of synaptic connections between neurons. Synaptic plasticity is the ability to alter synaptic connections between neurons that underlies learning and memory processes. Glutamate receptors mediate the majority of excitatory neurotransmission in the vertebrate nervous system. $N$-Methyl-D aspartate receptors (NMDARs) are one of the three pharmacologically distinct subtypes of glutamatergic ionotropic receptors. They are formed by heteromeric complexes which are usually comprised of essential GluN1 subunits and distinct NR2 (A-D) or NR3 subunits (Dingledine et al. 1999; Villmann et al. 1999; Cull-Candy et al. 2001). The opening of NMDAR channels, which are permeable to potassium, sodium, and calcium, requires simultaneous glutamate binding and postsynaptic membrane depolarization (McBain and Mayer 1994; Dingledine et al. 1999). This voltagedependent control of glutamate-induced calcium influx hints at the possibility that NMDARs serves as "Hebbian coincidence detectors" and as one of the molecular mechanisms eliciting synaptic plasticity (Tsien 2000).

Glutamatergic synapses undergo various forms of NMDARdependent changes in strength, a process thought to underlie some forms of learning and memory (Malenka and Nicoll 1999). One of the experimental models used to study the synaptic plasticity is based on long-term potentiation (LTP) of synaptic transmission. NMDA receptor antagonists block LTP induction and different forms of memory (Riedel et al. 2003). In addition, it

\footnotetext{
${ }^{2}$ These authors contributed equally to this work.

Corresponding authors: ramirof@fbmc.fcen.uba.ar, mpedreira@ fbmc.fcen.uba.ar

Article is online at http://www.learnmem.org/cgi/doi/10.1101//m.041707. 116.
}

has also been demonstrated that there is a post-training increase in GluN1 subunit expression in hippocampal membranes of rats trained in an inhibitory avoidance task (Cammarota et al. 2000; Moyano et al. 2004).

LTP dependent on NMDARs has been reported in the invertebrate model Aplysia californica (Lin and Glanzman 1994; Roberts and Glanzman 2003). The role of NMDARs in learning and memory processes was also demonstrated in several other invertebrates (Müssig et al. 2010; Amano and Maruyama 2011; Miyashita et al. 2012; Hepp et al. 2013). In our laboratory, research performed in the crab Neohelice granulata (formerly Chasmagnathus granulatus) using context associative learning (context signal memory, CSM) has indicated that NMDA-like receptors are involved in consolidation and reconsolidation (Pedreira et al. 2002; Troncoso and Maldonado 2002). Pharmacological-behavioral experiments have shown that systemic administration of the vertebrate NMDAR antagonists MK-801 and AP5 disrupts both processes of the contextual associative memory paradigm developed in our laboratory (Pedreira et al. 2002; Troncoso and Maldonado 2002; Barreiro et al. 2013). The function of these receptors is also necessary for the acquisition of extinction memory but not for its consolidation (Pérez-Cuesta et al. 2007). In a recent study, we characterized the GluN1-like subunit, and describe the distribution of NMDA-like receptors in the crab central nervous system (CNS). We identified two immunoreactive bands for the

(C) 2016 Hepp et al. This article is distributed exclusively by Cold Spring Harbor Laboratory Press for the first 12 months after the full-issue publication date (see http://learnmem.cshlp.org/site/misc/terms.xhtml). After 12 months, it is available under a Creative Commons License (Attribution-NonCommercial 4.0 International), as described at http://creativecommons.org/licenses/ by-nc/4.0/. 
GluN1-like subunit. The close proximity of the molecular weight of these bands suggests that they may represent post-translational modifications of one protein (Petralia et al. 1994; Rao and Craig 1997). These GluN1-like bands are present in all major ganglia of the CNS; in addition, the band intensities suggest anGluN1like homogenous distribution among ganglia. At the subcellular level, the GluN1-like subunit is only detectable in synaptosomes that illustrate the synaptic membrane localization of this protein (Hepp et al. 2013).

In general, changes in the functionality of NMDARs might be induced by the modification of the subunit's expression that form the receptor, or by phosphorylation which in turn modulates its interactions with other proteins. In addition, cellular trafficking of NMDARs has also been extensively studied (Wenthold et al. 2003). This trafficking does not only include movement of NMDARs between synaptic and extra-synaptic localizations at the surface of neurons but also the cycle between intracellular compartments and the plasma membrane (Groc et al. 2009). Thus, it was demonstrated that the receptors might change their position by lateral diffusion in the plasma membrane (Tovar and Westbrook 2002) or by trafficking receptors from the intracellular vesicles to insertion into the plasma membrane, a process called surface expression (Bard and Groc 2011). The aim of the present study was to analyze the surface expression of NMDAlike receptors during consolidation of the contextual learning in the crab $N$. granulata. To reach such a goal we used differential cross-linking with bis(sulfosuccinimidyl)suberate (BS3) to establish a GluN1 membrane/intracellular ratio. The ratio was calculated at different time points after training to establish the time course of learning-induced changes in surface expression. The surface expression of the GluN1 subunit of the NMDA receptor is down-regulated immediately after training, up-regulated $3 \mathrm{~h}$ after training and returns to the naïve and control levels $24 \mathrm{~h}$ after training. This effect was independent of GluN1 synthesis and only occurred in the central brain and not in the thoracic ganglion. To further study the pathway that underlies the changes in surface expression of the NMDA receptor subunit GluN1 we used bicuculline (Tano et al. 2013) (antagonist of $\mathrm{GABA}_{\mathrm{A}}$ receptors) to indirectly induce the activation of the glutamatergic pathway. There is evidence that bicuculline changes the GluN1 content at post-synaptic densities in cultured rat hippocampal neurons (Ehlers 2003). We observed a similar increment in surface expression of GluN1 in the central brain $3 \mathrm{~h}$ after the drug administration.

All in all these data suggest that in the crab $N$. granulata, NMDARs are involved in memory consolidation through fine regulation of their synaptic localization. These changes in surface expression of the NMDARs suggest a role in the stabilization of the learned task.

\section{Results}

Training with 30 trials generates a long-term context-signal memory trace in $N$. granulata

Presentation of a moving screen (visual danger stimulus, VDS) to each crab elicits an escape response that diminishes over 30 iterative presentations separated by
$100 \mathrm{sec}$. During the pretraining trial, trained ( $\mathrm{Tr}, N=17)$ and control groups (Ctl, $N=17$ ) show no significant differences in their escape response (Fig. 1A,B, PT). The response levels of the Tr group to the VDS reduces to levels below Ctl group basal activity (Fig. 1A, inset). This suggests a strategy change in the trained animals. Twenty-four hours after training, Tr and Ctl groups are evaluated with six VDS presentations in the same context where they were trained, and analyzed in two blocks: first testing trial and retraining from the second to the sixth trial. A significantly lower response is observed in the $\mathrm{Tr}$ animals for the first testing trial $(p<0.05)$ as for the remaining five trials, when compared with Ctl group animals $(p<0.01)$ (Fig. 1A,B). This response difference between groups in the testing session is defined as retention of the learned context-signal association. All the following experiments were performed with a replicate in which one was used for a biochemical experiment and the second was evaluated for memory retention. The corresponding biochemical data was used only if the replicate performed with animals from the same population showed significant memory retention at the first testing trial.

\section{GluN1 subunit of the NMDA receptor in the crab $N$. granulata is detected by antibodies to the carboxyl-terminus of the protein}

Previous physiological and immunohistochemical evidences indicate that the NMDAR is present in the crab nervous system (Hepp et al. 2013) and is necessary for the consolidation of the context signal memory (CSM) (Troncoso and Maldonado 2002; Pérez-Cuesta et al. 2007) In previous work from our laboratory, the NMDA receptor subunit GluN1 was characterized and its localization in the nervous system as well as its distribution at cellular level was described (Hepp et al. 2013). In that opportunity, a polyclonal antibody directed at a peptide corresponding to the amino acids 909-938 of the rat GluN1 subunit was used (Chemicon, AB1516). To further characterize the GluN1 receptor
A

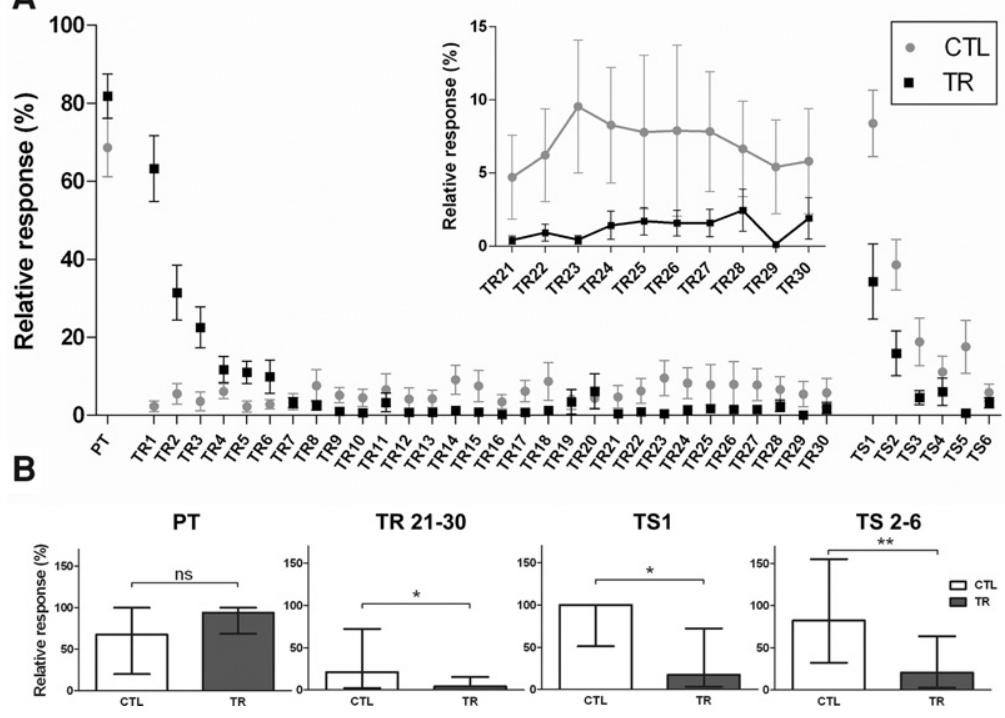

Figure 1. Training and retention testing of the context signal memory in the crab N. granulata. $(A)$ Relative response (\%) means and SEM for pretraining trial (one stimulus presentation, to equilibrate the response level of the groups), training (day 1 ) and testing (day 2), control group (Ctl, 30 recordings of basal activity with $100 \mathrm{sec}$ interrecordings interval) and training groups ( $\mathrm{Tr}, 30$ recordings during stimulus presentations, with $100 \mathrm{sec}$ intertrial interval). (B) Comparison of the response level for Ctl and $\mathrm{Tr}$ groups during pretraining (PT) (no significant differences), the block between training trail 21-30 (Tr 21-30 (*) p < 0.05), the first testing trial (TS1, $\left.\left(^{*}\right) \mathrm{p}<0.05\right)$ and the block between testing trial 2 and 6 (TS2-TS6, $\left({ }^{* *}\right) \mathrm{p}<00.1$ ). Animals per group, $n=17$. 
A

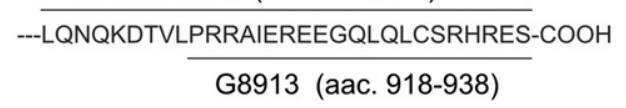

B

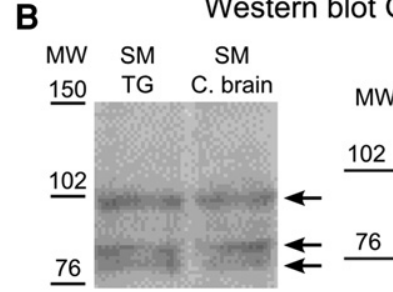

C

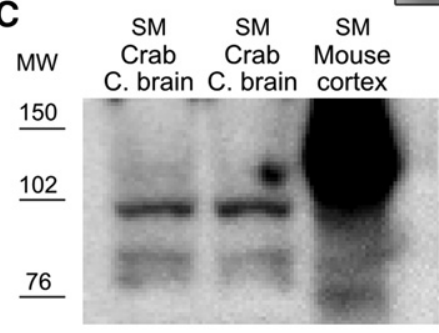

G8913 $\begin{array}{ll}\text { SM } & \text { SM } \\ \text { TG } & \text { TG }\end{array}$
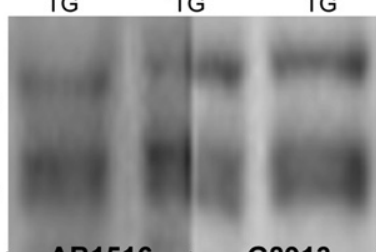

AB1516 SM $\quad$ SM SM Crab Mouse

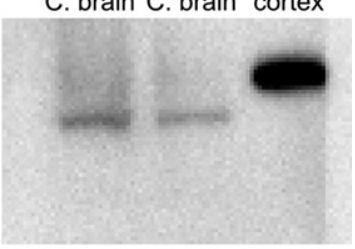

G8913 + Peptide

Figure 2. Antibodies against rat GluN1 cross-react with a GluN1 like protein in crab. $(A)$ Comparison of the sequence corresponding to the carboxy-terminal GluN1 subunit of rat recognized by antibodies AB1516 and G8913. (B) Western blot assay using two anti-rat GluN1 antibodies. Synaptosomal membrane extracts from crab thoracic ganglion (SM TG) and from crab brain (SM Brain). The AB1516 antibody was used for the left panel and the first lane and half of the second lane of the right panel, while the G8913 antibody was used for the second half of the second lane and third lane of the right panel. Arrows indicate the bands for GluN1membrane fraction at $\sim 102 \mathrm{kDa}$ and intracellular fraction at $\sim 88$ and $\sim 84 \mathrm{kDa}$. (C) Western blots with the G8913 antibody left panel and with same antibody preincubated with the peptide that was used to make the antibody to discern the specific bands in the immunoblot, right panel, for both panels the samples were SM of Crab brain for the first two lanes and SM of mouse cortex for the third lane. Mw, molecular weight $(\mathrm{kDa})$.

subunit in the crab and explore the receptor expression during long-term memory consolidation, we used an antibody directed to a sequence overlapping the one recognized by AB1516, G8913 Sigma-Aldrich (Fig. 2A). The signal for the AB1516 antibody is similar in both the central brain and thoracic ganglion (Fig. 2B, left panel). The G8913 antibody yields a similar signal when compared in the same lane of a Western blot, and two adjacent lanes, one for each antibody (Fig. 2B, right panel). The peptide described in Figure 2A was preincubated with the G8913 antibody and the specificity of the two lower bands evidenced by the antibody (at $\sim 88$ and $\sim 84 \mathrm{kDa}$ ) was demonstrated (Fig. 2C). All of this evidence further supports that the evaluated protein is, in fact, a subunit of the crab homolog of the NMDA receptor.

\section{Expression of the GluN1 subunit of the NMDA receptor} in the central brain is not affected during consolidation To evaluate the expression of the GluN1 subunit during consolidation of the CSM, we choose the central brain of N. granulata, a structure involved in this type of learning (Freudenthal et al. 1998). Total central brain homogenate from trained and control animals were obtained immediately after training or 3-h posttraining, and were compared with that of Naïve animals (Nv) in a Western blot assay (Fig. 3). Actin was used as a loading control;

the signal obtained for the GluN1 of each animal was normalized to the actin content of the same line. The amount of the GluN1 subunit observed in the total central brain homogenates from Tr, Ctr, and Nv did not differ at the times evaluated $(0 \mathrm{~h}$ : $\operatorname{Tr} n=$ 14, Ctr $n=15$, Nv $n=17 ; 3$ h: Tr $n=5$, Ctr $n=6$, Nv $n=5$ ) (Fig. 3). This result suggests that the total amount of GluN1 does not change significantly during consolidation at the time points evaluated.

\section{Assessment of membrane NMDA receptor GluN1 subunit with surface expression assay}

To identify the proportion of membrane GluN1 of the total GluN1 we use the differential cross-linking with bis(sulfosuccinimidyl)suberate (BS3). Using BS3 on the tissue, on top of the original bands, a signal corresponding to a complex containing GluN1 appears approximately at the level of the $200 \mathrm{kDa}$ marker (Fig. 4A,B). Similar bands appear when the BS3 cross-linking agent was applied to the central brain and the thoracic ganglion (Fig. 4A). Cross-linking for 1,3 , or $5 \mathrm{~d}$, show similar intensities for the high molecular weight bands (Fig. 4A). Since BS3 does not cross the plasmatic membrane, cross-linking takes place only between proteins with an extracellular domain (Grosshans et al. 2002b). As shown in previous studies (Hall and Soderling 1997), when treating with BS3, the high molecular weight bands appear only when immunoblotting for a membrane protein (GluN1) but not for a protein that has no extracellular domains (actin) (Fig. 4B).

\section{Training induces changes in surface expression of GluN1} in the central brain but not in the thoracic ganglion

We evaluated if learning affects the membrane/intracellular ratio of GluN1. We trained animals as described in Figure 1 and the localization of the GluN1 subunit was evaluated by Western blot analysis at different time points after training. The central brains were dissected and were treated with BS3 for the Nv, Tr, and Ctl animals at 0-, 3-, and 24-h post-training. The BS3 tissue treatment allowed us to identify the extracellular and intracellular GluN1 in total homogenates. Immediately after training there is a significant decrease of the GluN1 subunit expressed at the membrane surface for $\mathrm{Tr}$ animals compared with $\mathrm{Ctl}$ and $\mathrm{Nv}$ animals (ANOVA $F_{(2,15)}=7.99 ; P=0.004$; Fisher-LSD; Nv-Tr, $P<0.01$; Ctl-Tr, $P<0.05$; Ctl-Nv, NS.). At 3-h post-training there is an increase of the membrane/intracellular ratio for Tr animals compared with $\mathrm{Nv}$ animals (ANOVA, $F_{(2,14)}=3.99 ; \quad P=0.042$; Fisher-LSD; Nv-Tr, $P<0.05$ ) (Fig. 5A). At 24-h post-training there is no significant differences in the GluN1 surface expression between groups (Fig. 5A). The thoracic ganglia were extracted and treated with BS3 at 0- and 3-h post-training and the membrane/ intracellular ratio was assessed. There was no significant difference for membrane surface expression of the GluN1 subunit in the thoracic ganglion during consolidation (Fig. 5B). These data suggest that the GluN1 subunit membrane exposure is affected during memory consolidation in the nervous system area described to be involved in learning and memory processes (Freudenthal and Romano 2000).

\section{Surface expression of GluN1 is affected after systemic administration of bicuculline}

To further study the pathway that underlies the membrane trafficking of the NMDA receptor subunit GluN1 we used bicuculline as an indirect way to induce glutamatergic activation and thus evaluate the effect on membrane surface exposure of the receptor. Three increasing doses of bicuculline were tested and the membrane/intracellular ratio was evaluated in the central brain $3 \mathrm{~h}$ 

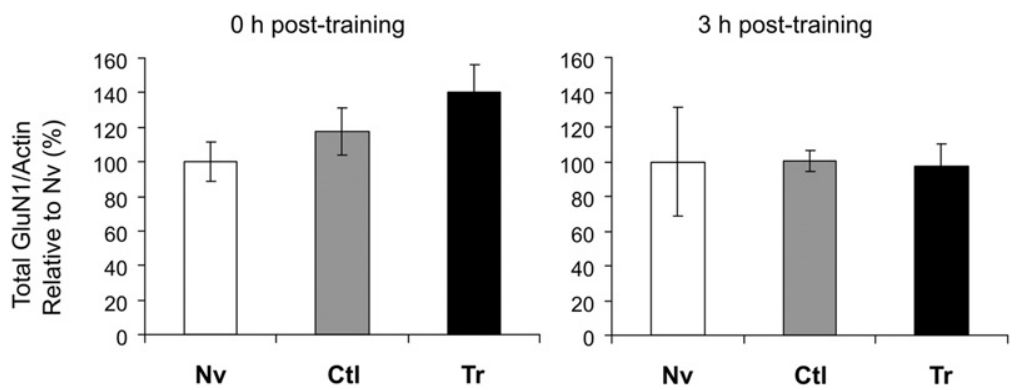

Figure 3. Total GluN1 subunit/actin in whole-central brain extracts relative to Naïve. The amount of total GluN1 was evaluated for the Naïve (Nv), Control (Ctl), and Trained (Tr) groups at different times post-training: 0 hours $(0 \mathrm{~h})$ and 3 hours $(3 \mathrm{~h})$. Actin was used as a loading control and values are shown relative to $\mathrm{Nv}(\%)$.

after the systemic injection. As seen previously in Fig. 5, at 3-h post-training the membrane/intracellular NMDAR ratio increases, therefore this time was the one used to evaluate the effects of systemic bicuculline injection. A significant increase in the membrane/intracellular ratio was observed with a dose of $10 \mu \mathrm{g} / \mathrm{g}$ 3-h post-injection $(\mathrm{MEAN}=149.4, \mathrm{SEM}=14.5, P<0.05$ ) (Fig. 6 ). No significant increase was observed for the $3 \mu \mathrm{g} / \mathrm{g}$ and the $15 \mu \mathrm{g} / \mathrm{g}$ dose showed a tendency for increase that was not statistically confirmed. This suggests that increased membrane exposure of the NMDA receptor subunit GluN1 observed $3 \mathrm{~h}$ after neuronal activation may provide a mechanism through which the change in membrane exposure during consolidation is achieved.

\section{Discussion}

In this study, we show that memory consolidation affects surface expression of GluN1 subunit while not affecting the total expression of the protein.

CSM training in the crab Neohelice induces a memory with a strong retention at $24 \mathrm{~h}$, when comparing $\mathrm{Tr}$ animals that were exposed to 30 iterative presentations of the VDS with Ctl animals that were exposed to the context with no VDS presentation (Fig. 1).

Here we find a specific signal for the NMDA receptor subunit GluN1. The specific bands are detected when using two different antibodies directed against the carboxy terminus of GluN1, as shown in our previous work (Hepp et al. 2013), and by the competition with the antigenic peptide shown in Figure 2C. This signal is detected both in the central brain and in the thoracic ganglion of the crab (Figs. 2B, left panel and 4A). The GluN1 comparison between these two areas is important because the central brain is relevant for memory consolidation as shown by Freudenthal and Romano (2000).

The total protein levels of the NMDA receptor subunit GluN1 in the central brain of $\mathrm{Ctl}$ and $\mathrm{Tr}$ animals do not differ from the levels in $\mathrm{Nv}$ animals, immediately after and 3-h post-training (Fig. 3). This led us to the idea that the regulation of the receptor was not at the protein expression level as seen in other memory models (Baez et al. 2013) but rather at the surface expression level. The regulation at the surface expression level has been repeatedly reported in memory and synaptic plasticity experiments (Cammarota et al. 2000; Grosshans et al. 2002b; Moyano et al. 2004; Mukherjee et al. 2014).

To evaluate how much of the total protein was either exposed at the plasma membrane or was intracellular, we adapted the surface expression assay using BS3 cross-linking, previously used for AMPA and NMDA receptors (Hall and Soderling 1997; Grosshans et al. 2002b; Boudreau et al. 2012), to the crab nervous system (Fig. 4). The increment in surface expression of the NMDA receptor measured by the BS3 technique positively correlates with changes in NMDA currents in rat CA1 region of the hippocampus (Grosshans et al. 2002a,b). Therefore, we consider that NMDA surface expression observed by BS3 technique corresponds to functional receptors. Furthermore, the BS3 technique is reliable to evaluate surface expression, yielding similar results as other techniques of surface modification of receptors such as chymotripsin, biotinilation, and radioactive ligand binding (Hall and Soderling 1997; Grosshans et al. 2002b).

This protocol yielded separated signals for the membrane cross-linked GluN1 and the intracellular GluN1, and this crosslinking did not affect other intracellular proteins as shown with actin (Fig. 4B). Grosshans et al. (2002b) showed that the surface expression assay is able to detect increments in the NMDA receptor subunit GluN1 (indirectly through a decrease in intracellular GluN1) induced after a high-frequency stimulation that yields long-term potentiation. In our experiments, surface expression assays during consolidation indicate that the GluN1 subunit decreased in trained animals immediately after training when compared with $\mathrm{Nv}$ and Ctl animals in the central brain. This change was not general to the whole nervous system as shown by the unchanged levels shown among Nv, Ctl, and Tr animals in the thoracic ganglion (Fig. 5). Three hours post-training the surface expression of GluN1 in the central brain of Tr animals shows an increment when compared with $\mathrm{Nv}$ and Ctl animals, and again the change is seen only in the central brain and not in the thoracic ganglion (Fig. 5). The central brain levels of surface GluN1 are

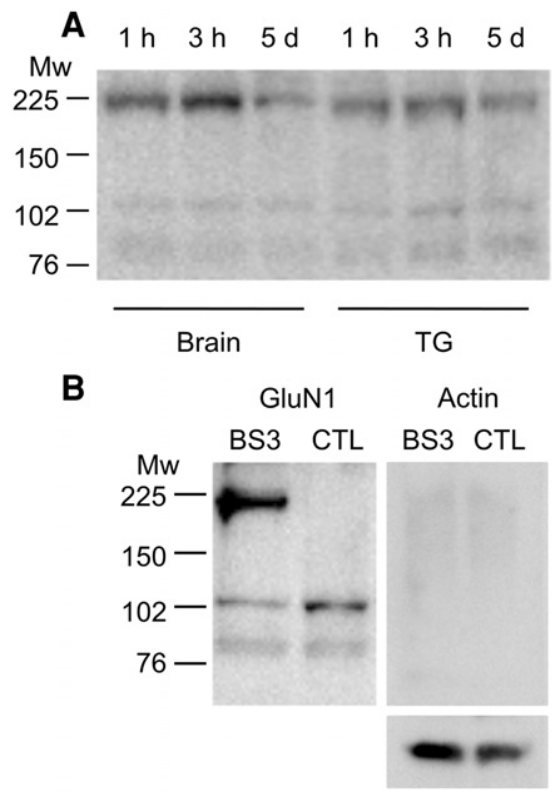

Figure 4. Membrane exposure assay with BS3. (A) Total extracts of central brain and thoracic ganglion treated with BS3 for different times: 1 hour ( $1 \mathrm{~h}), 3$ hours $(3 \mathrm{~h})$, and 5 days $(5 \mathrm{~d})$. (B) Total extracts of thoracic ganglia treated with BS3 (BS3) or control (CTL). Left panel, AB1516 antibody for the GluN1 subunit; right panel, antibody for actin. Mw: molecular weight $(\mathrm{kDa})$. 
A

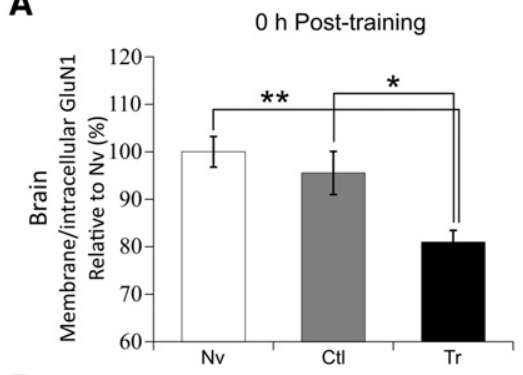

B

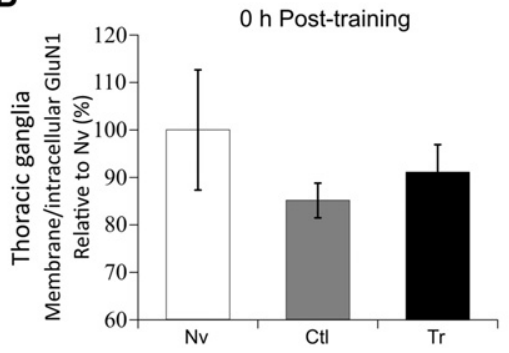

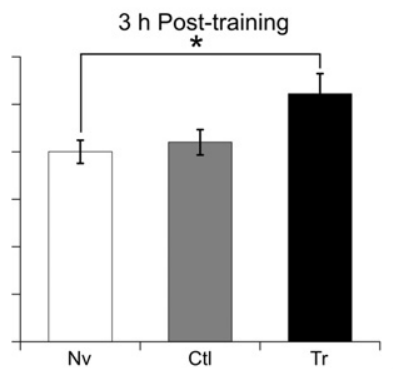

$3 \mathrm{~h}$ Post-training

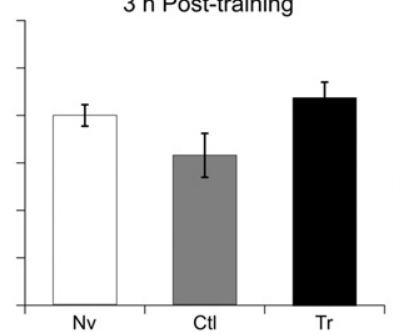

$24 \mathrm{~h}$ Post-training

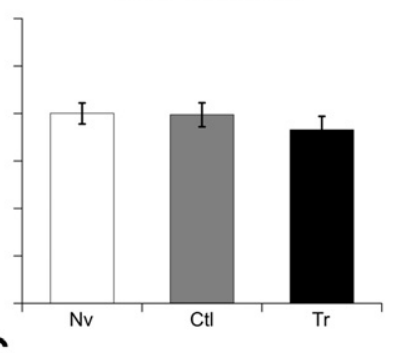

C

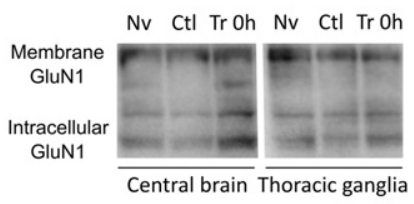

Figure 5. Membrane/intracellular GluN1 relation in the central brain and thoracic ganglion during consolidation. Bars represent mean and SEM of the relation between membrane GluN1 fraction and intracellular GluN1 fraction expressed as percentage of the average relation determined in simultaneously treated Naive (Nv) animals. Nv, control (Ctl) and trained (Tr) animals were treated with BS3 at different times post-training. (A) Central brain 0-h post-training (left panel, $n=6$ for each group), 3-h post-training (center panel, $n=6$ for each group), and 24-h post-training (right panel, $n=10$ (Nv y Tr) and $n=14(\mathrm{Ctl})) .\left({ }^{*}\right) P<0.05$ and $\left({ }^{* *}\right) P<0.01$ for statistical differences between groups after ANOVA. (B) Thoracic ganglion 0-h post-training (left panel, $n=6$ for each group) and 3-h post-training (right panel, $n=6$ for each group). (C) Representative Western blot with the G8913 antibody of extracts obtained in Nv, Ctl, and Tr groups at 0-h post-training for central brain (left panel) and thoracic ganglion (right panel).

similar between the three animal groups when assessed 24 -h posttraining (Fig. 5).

During the initial part of LTP, the membrane ratio of splice variants of GluN1 dramatically changes (Grosshans et al. 2002b). One possibility is that the initial decrement in surface expression of GluN1 seen in the crab central brain immediately after training could be reflecting endocytosis of this subunit that is part of a splice variant rearrangement. Surface expression of GluN1 is augmented during LTP in rat CA1 area of the hippocampus from $30 \mathrm{~min}$ after high frequency stimulation until at least $3 \mathrm{~h}$, in a time window that agrees with the plasticity seen in the crab during consolidation (Grosshans et al. 2002a). It has been proposed that NMDARs can significantly contribute to information transfer at synapses during periods of repetitive activity (Hunt and Castillo 2012), such as the CSM learning task, which relies on iterative presentations of the stimulus. These changes in the surface GluN1 of Tr animals during consolidation may be a form of metaplasticity, in which the changes in NMDA receptors suggest a shift in the threshold to undergo further plasticity.

In an attempt to address if the observed trafficking of GluN1 is elicited by neuronal activity, we used systemic bicuculline injections (antagonist of $\mathrm{GABA}_{\mathrm{A}}$ receptors) in incremental doses and evaluated surface expression 3-h post-injection. The level of surface GluN1 in the central brain was incremented by injection of $10 \mu \mathrm{g} / \mathrm{g}$ dose of bicuculline but not by a $3 \mu \mathrm{g} / \mathrm{g}$ dose (Fig. $6 \mathrm{~A}$ ). The results from injected animals suggest that glutamatergic activity is a candidate for the changes seen in GluN1 surface expression during consolidation (Fig. 6). Mukherjee et al. (2015) describe an initial decrease of NMDAR surface expression after training followed by a later increase in rat anterior piriform cortex.

Neuronal activity in the central brain during consolidation could be changing the levels of functional NMDA receptor subunit GluN1. These changes could be reflecting time specific requirements at the synapses. A decrement in surface GluN1 immediately after training, would not allow further activation through the receptor, calling for specificity on other synapses. On the contrary, the increment in surface GluN1 3-h post-training, once the consolidation processes is advanced, could reflect a higher probability for activation (Mukherjee et al. 2015).

This is the first time that a change in NMDA receptor surface expression during long-term memory consolidation is described in an invertebrate. Altogether, these results show a consolidation landscape where NMDA receptors, the coincidence detectors, have a more dynamic regulation than previously thought, thus contributing to mechanisms of memory consolidation. This work provides important groundwork and opens questions to investigate metaplasticity mechanisms in learning and memory.

\section{Materials and Methods}

\section{Animals}

We used adult male intertidal crabs ( $N$. granulata, formerly Chasmagnathus granulatus), measuring $2.7-3.0 \mathrm{~cm}$ across the

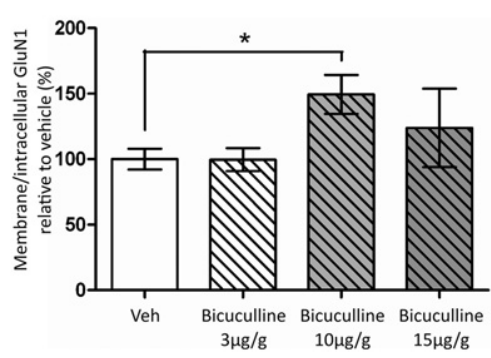

Figure 6. Membrane/intracellular relation of GluN1 after systemic injections bicuculline. Membrane/intracellular GluN1 relation in the central brain treated with BS3 at 3-h post-injection of different concentrations of bicuculline $(3,10$, and $15 \mu \mathrm{g} / \mathrm{g})$ or vehicle (Veh) ANOVA, $\left({ }^{*}\right)$ $P<0.05 . N=14$. 
carapace and weighing $\sim 17 \mathrm{~g}$. The crabs were collected from water $<1 \mathrm{~m}$ deep in narrow coastal inlets (rías) of San Clemente del Tuyú, Buenos Aires Province, Argentina. Once transported to the laboratory, they were housed in plastic tanks $(35 \times 48 \times 27$ $\mathrm{cm}$ ) filled to a depth of $2 \mathrm{~cm}$ with diluted marine water (Red sea fish pharm) with a salinity of $1.0 \%-1.4 \%$ and a $\mathrm{pH}$ of $7.4-7.6$. The water was changed every $2 \mathrm{~d}$. The holding room was maintained on a 12-h light-dark cycle (lights on from 07:00-19:00 h) and the temperature was maintained between $22^{\circ} \mathrm{C}-24^{\circ} \mathrm{C}$. Experiments are performed only in males to avoid disrupting the natural population or crabs. Females carry the fecundated eggs in the first stages of development and capturing them might affect the size of the population. Another factor considered is that a natural population has many sources of variability and selecting male animals restricts variables such as size range. The reported research was conducted in accordance with the local regulations for the care and use of laboratory animals. All experiments were done in accordance to local regulations to minimize animal suffering and the number of animals used.

\section{Drugs and injection procedure}

Dimethyl sulfoxide (DMSO) was used as the vehicle. Ten microliters of vehicle or drug solution was given through the right side of the dorsal cephalothoracic-abdominal membrane by means of a syringe fitted with a sleeve to control the depth of penetration to $4 \mathrm{~mm}$, thus ensuring that the injected solution was released in the pericardial sac. Bicuculline, the competitive antagonist of $\mathrm{GABA}_{\mathrm{A}}$ receptors, was purchased from Fluka Analytical and used in concentrations of 3,10 , and $15 \mu \mathrm{g} / \mathrm{g}$.

\section{Training and testing procedures}

The apparatus used for training and measure of escape response is described in detail elsewhere (Romano et al. 1990). Briefly, the experimental unit was the actometer: a bowl shaped plastic container with a steep concave wall and a circular central flat floor $10 \mathrm{~cm}$ in diameter, covered to a depth of $0.5 \mathrm{~cm}$ with salt water. The crab was lodged in the container, which was suspended by three strings from an upper wooden framework $23 \times 23 \times 30 \mathrm{~cm}$. and illuminated by a $5 \mathrm{~W}$ lamp placed $30 \mathrm{~cm}$ (Tano et al. 2013) above the animal. A motor-operated screen (US, an opaque rectangular strip of $25.0 \times 7.5 \mathrm{~cm}$ ) was moved horizontally over the animal from left to right, and vice versa. The screen's movements were cyclical. The screen displacements provoked the escape response of the crab and subsequent container vibrations. Four microphones were attached to the center of the outside base of the container. The microphones recorded the vibrations that were produced by the animal's response. These signals were amplified, integrated during the entire trial $(9 \mathrm{sec})$ and translated into arbitrary numerical units ranging from 0 to 8000 . Each trial lasted $5 \mathrm{sec}$ and consisted of two cycles of stimulation (four screen presentations over the actometer), the recorded crab activity during the entire trial time is integrated. The experimental room has 40 actometers, isolated from each other by partitions. A computer is used to program trial sequences, trial duration $(5 \mathrm{sec})$ and inter-trial interval (ITI, $100 \mathrm{sec}$ ), as well as to monitor experimental events. Trained animals received 30 trials of 5-sec duration, with 100-sec ITI and control animals were recorded during the same periods as the trained ones but without the screen presentation. All training sessions were preceded by $10 \mathrm{~min}$ of adaptation time in the actometer, after this adaptation period all animals (trained and control) receive one pretraining trial (PT) with screen presentation. This presentation response is used to distribute the animals in two groups ( $\mathrm{Tr}$ and $\mathrm{Ctl}$ ) with similar response levels and for the percent normalization of each crab. Training sessions lasted 50 min for both groups. The testing session is performed $24 \mathrm{~h}$ after training, with six trials. Crabs were individually housed during the entire inter-session interval in plastic containers, covered to a depth of $0.5 \mathrm{~cm}$ with seawater and kept inside dimly lighted drawers. The maximal response of an animal during a trial (PT, training or testing) is taken as a $100 \%$ response and all other responses are normalized to this value. This procedure minimizes differences between animals due to factors other than the training (animal weight, motor vibration differences). The level of response at testing session was compared between trained and control groups. Retention of the learning acquired during training was considered when a statistically lower level of response was found in trained group in comparison to control group.

\section{Protein extracts}

The animals were anaesthetized by immersion in an ice/salt water mix for $5 \mathrm{~min}$ at $0-, 3-$, or 24 -h post-training or injection. The central brains and thoracic ganglia were dissected. For each sample, 4-6 central brains or thoracic ganglia where pooled in $1 \mathrm{~mL}$ of buffered crab saline solution ( $\mathrm{pH}$ 7.4).

\section{Total homogenates}

Pooled central brains or thoracic ganglia where homogenized in $150 \mu \mathrm{L}$ of hyposmotic solution containing 1\% SDS and protease inhibitors (phenylmethylsulfonyl fluoride [PMSF $0.5 \mathrm{mM}$, aprotinine $10 \mu \mathrm{g} / \mathrm{mL}$, leupeptine $10 \mu \mathrm{g} / \mathrm{mL}$, pepstatine A $1 \mu \mathrm{g} / \mathrm{mL})$, using a glass-glass tight dounce homogenizer. Samples where centrifuged for $10 \mathrm{~min}$ at $10000 \mathrm{~g}$ and the supernatant was separated and stored at $-80^{\circ} \mathrm{C}$ until use.

\section{Synaptosomal extracts}

The extracts enriched in synaptosomal membranes were obtained as follows: The dissected tissues were homogenized in $750 \mu \mathrm{L}$ of cold homogenization buffer $(20 \mathrm{mM}$ Tris- $\mathrm{HCl}, 900 \mathrm{mM}$ sucrose, $1 \mathrm{mM}$ EDTA, pH 7.8), with protease inhibitors (as in total homogenates) with a glass-glass homogenizer. The tissue homogenates were centrifuged $\left(4^{\circ} \mathrm{C}, 1000 \mathrm{~g}, 10 \mathrm{~min}\right)$ to produce a pellet $(\mathrm{P} 1)$ and a supernatant $(\mathrm{S} 1)$. $\mathrm{S} 1$ was collected and the $\mathrm{P} 1$ was resuspended in $500 \mu \mathrm{L}$ of the homogenization buffer and centrifuged $\left(4^{\circ} \mathrm{C}\right.$, $1000 \mathrm{~g}, 10 \mathrm{~min}$ ) to obtain a pellet (P10) and supernatant (S10). P10 was resuspended in $30 \mu \mathrm{L}$ of cold hyperosmotic buffer $(20 \mathrm{mM}$ HEPES, pH 7.9; $1.2 \mathrm{M} \mathrm{KCl} ; 1.5 \mathrm{mM} \mathrm{MgCl} 2 ; 0.4 \mathrm{mM}$ EDTA; 0.5 mM DTT; 50\% glycerol, pepstatin A, $1 \mu \mathrm{g} / \mathrm{mL}$; leupeptin, $10 \mu \mathrm{g} /$ $\mathrm{mL} ; 0.5 \mathrm{mM}$ PMSF; and aprotinin, $10 \mu \mathrm{g} / \mathrm{mL}$ ) and centrifuged $\left(4^{\circ} \mathrm{C}, 10,000 \mathrm{~g}, 15 \mathrm{~min}\right)$. The supernatant corresponds to the nuclear extract and the pellet was discarded. S1 and S10 were combined and centrifuged at $13,000 \mathrm{~g}$ for $30 \mathrm{~min}$ to obtain a pellet (P2, enriched in synaptosomes) and a supernatant (S2, cytoplasmatic extract). P2 was resuspended in $200 \mu \mathrm{L}$ of cold hyposmotic buffer (5 mM Tris- $\mathrm{HCl}, 50 \mathrm{mM} \mathrm{CaCl}_{2}, \mathrm{pH} 8.1$ ), sonicated at $49 \%$ for $3 \mathrm{sec}$ and centrifuged $(15,800 \mathrm{~g}, 50 \mathrm{~min})$ to produce a pellet $(\mathrm{P} 3$, enriched in synaptosomal membranes) and a supernatant (S3, enriched in synaptosomal content). P3 was resuspended in $30 \mathrm{~mL}$ of hyposmotic buffer-1\% sodium dodecyl sulfate (SDS).

\section{BS3-treated extracts}

Pooled central brains or thoracic ganglia where washed twice by placing them in HSE buffer $(2 \mathrm{mM})$ with protease inhibitors on a shaker and centrifuging for $2.5 \mathrm{~min}$ at $1000 \mathrm{~g}$. Central brains or thoracic ganglia where transferred to a new tube and incubated in $150 \mu \mathrm{L}$ (for thoracic ganglia) or $100 \mu \mathrm{L}$ (for central brains) in HSE buffer with $3 \mathrm{mM}$ of BS3 for $1,3 \mathrm{~h}$ or $5 \mathrm{~d}$ on a refrigerated $\left(4^{\circ} \mathrm{C}\right)$ shaker. These fixation times where used for experiment in Figure 4, all other experiments involving BS3 where incubated for $1 \mathrm{~h}$ with the fixating agent. After incubation with BS3 samples were washed twice with HSE buffer as described in the first step of this protocol. Samples were transferred to a new tube and homogenized in $200 \mu \mathrm{L}$ (for thoracic ganglia) or $75 \mu \mathrm{L}$ (for central brains) of HSE buffer with 1\% SDS and protease inhibitors. Samples were stored at $-80^{\circ} \mathrm{C}$ until use.

\section{Western blots}

Loading buffer $(4 \times)$ was added to each sample (35 $\mu \mathrm{g}$ of protein), which was then denatured (boiled for $5 \mathrm{~min}$ at $100^{\circ} \mathrm{C}$ ). Then the samples were electrophoresed using 10\% SDS-polyacrylamide gel electrophoresis (PAGE) at $100 \mathrm{~V}$ for $1 \mathrm{~h}$ and then electroblotted 
to PVDF membrane (Bio-Rad) at $100 \mathrm{~V}$ for $1 \mathrm{~h}$. The blots were blocked in blocking buffer (10\% low-fat dry milk in Tris-buffered saline $-0.1 \%$ Tween 20 [TBS-T], $\mathrm{pH} 7.6$ ) for $1 \mathrm{~h}$ at room temperature. After two 15-min washes with TBS-T, the blots were incubated overnight $\left(4^{\circ} \mathrm{C}\right)$ with a primary antibody, for either NMDA GluN1 or actin. For the AB1516 antibody (Chemicon), a 1:100 dilution in PBS-T was used. For the G8913 antibody (SigmaAldrich) a 1:400 dilution with T-TBS was used. For the actin antibody (Santa Cruz Biotechnology) a 1:1000 dilution in T-TBS was used. After six 10-min washes with TBS-T, the blots were incubated with horseradish peroxidase (HRP)-conjugated goat anti rabbit IgG (1:5000 dilution in TBS-T, $1 \mathrm{~h}, 25^{\circ} \mathrm{C}$; Santa Cruz Biotechnology; sc-2030), followed by four washes of $10 \mathrm{~min}$ each with TBS-T. Detection was made with the Advanced ECL detection kit (GE Amersham) as described by the manufacturer, and the signals were digitized by a FUJI FILM-Intelligent Dark Box II apparatus with image reader LAS-1000 software. The protein size was estimated by its relative mobility using ImageJ 1.293 software (NIH) and correlating these measurements with the molecular weights of prestained standard proteins (Full-Range Rainbow Molecular Weight Markers: 12-225 kDa, Amersham).

\section{Data analysis}

Mann-Whitney test was used to analyze the Pretraining trial, the sum of the training trials from 21 to 30 (TR 21-30), the first testing trial (TS1) and the sum of testing trials 2-6 (TS 2-6).

For Western blots, optic density (OD) was measured using Image software and statistical analysis was performed using oneway ANOVA, with Fisher-LSD post hoc multiple comparisons.

The data submitted complies with ANOVA requirements such as normality and homogeneity of variances. When normality and homogeneity was not met, nonparametric Kruskal-Wallis analysis was used.

\section{Competing interest statement}

The authors have no conflict of interest.

\section{Acknowledgments}

We thank Angel Vidal for technical assistance and Dr. Arturo Romano and Dr. Fernando Locatelli for helpful discussions and revision of the article. We thank Kevin Michael Boergens for language revision of the manuscript. This work was supported with grants from the University of Buenos Aires (UBACyT 2011-2014 20020100200268, UBACyT 2014-2017 20020130200283BA), from the CONICET (PIP 2011-2013: 11220100100169) and from FonCyT (Grant PICT2010-0391, Grant PICT2013-1657, Grant PICT2013-0412).

Authors' contributions: All authors had full access to all the data in the study and take responsibility for the integrity of the data and the accuracy of the data analysis. Study concept and design: M.E.P. and R.F. Acquisition of data: Y.H., A.S., M.C.T., and R.F. Analysis and interpretation of data: Y.H., A.S., M.E.P., and R.F. Drafting of the article: Y.H., A.S., M.E.P., and R.F. Critical revision of the article for important intellectual content: Y.H., A.S., M.C.T., M.E.P., and R.F. Statistical analysis: Y.H., A.S. and R.F. Funding: M.E.P. and R.F. Administrative, technical, and material support: M.E.P. and R.F. Study supervision: M.E.P. and R.F.

\section{References}

Amano H, Maruyama IN. 2011. Aversive olfactory learning and associative long-term memory in Caenorhabditis elegans. Learn Mem 18: 654-665.

Baez MV, Oberholzer MV, Cercato MC, Snitcofsky M, Aguirre AI, Jerusalinsky DA. 2013. NMDA receptor subunits in the adult rat hippocampus undergo similar changes after 5 minutes in an open field and after LTP induction. PLoS One 8: e55244.

Bard L, Groc L. 2011. Glutamate receptor dynamics and protein interaction: lessons from the NMDA receptor. Mol Cell Neurosci 48: $298-307$.
Barreiro KA, Suárez LD, Lynch VM, Molina VA, Delorenzi A. 2013. Memory expression is independent of memory labilization/reconsolidation. Neurobiol Learn Mem 106: 283-291.

Boudreau AC, Milovanovic M, Conrad KL, Nelson C, Ferrario CR, Wolf ME. 2012. A protein cross-linking assay for measuring cell surface expression of glutamate receptor subunits in the rodent brain after in vivo treatments. Curr Protoc Neurosci Chapter 5: Unit 5.30.1-19.

Cammarota M, de Stein ML, Paratcha G, Bevilaqua LR, Izquierdo I, Medina JH. 2000. Rapid and transient learning-associated increase in NMDA NR1 subunit in the rat hippocampus. Neurochem Res 25: $567-572$.

Cull-Candy S, Brickley S, Farrant M. 2001. NMDA receptor subunits: diversity, development and disease. Curr Opin Neurobiol 11: 327-335.

Dingledine R, Borges K, Bowie D, Traynelis SF. 1999. The glutamate receptor ion channels. Pharmacol Rev 51: 7-61.

Ehlers MD. 2003. Activity level controls postsynaptic composition and signaling via the ubiquitin-proteasome system. Nat Neurosci 6: $231-242$

Freudenthal R, Romano A. 2000. Participation of Rel/NF-кB transcription factors in long-term memory in the crab Chasmagnathus. Brain Res $\mathbf{8 5 5}$ $274-281$.

Freudenthal R, Locatelli F, Hermitte G, Maldonado H, Lafourcade C, Delorenzi A, Romano A. 1998. к-B like DNA-binding activity is enhanced after spaced training that induces long-term memory in the crab Chasmagnathus. Neurosci Lett 242: 143-146.

Groc L, Bard L, Choquet D. 2009. Surface trafficking of N-Methyl-D-aspartate receptors: physiological and pathological perspectives. Neuroscience 158: $4-18$.

Grosshans DR, Clayton DA, Coultrap SJ, Browning MD. 2002a. LTP leads to rapid surface expression of NMDA but not AMPA receptors in adult rat CA1. Nat Neurosci 5: 27-33.

Grosshans DR, Clayton DA, Coultrap SJ, Browning MD. 2002b. Analysis of glutamate receptor surface expression in acute hippocampal slices. Sci STKE 2002: pl8.

Hall RA, Soderling TR. 1997. Differential surface expression and phosphorylation of the N-Methyl-D-aspartate receptor subunits NR1 and NR2 in cultured hippocampal neurons. J Biol Chem 272: 4135-4140.

Hepp Y, Tano MC, Pedreira ME, Freudenthal RAM. 2013. NMDA-like receptors in the nervous system of the crab Neohelice granulata: a neuroanatomical description. J Comp Neurol 521: 2279-2297.

Hunt DL, Castillo PE. 2012. Synaptic plasticity of NMDA receptors: mechanisms and functional implications. Curr Opin Neurobiol 22: $496-508$

Lin XY, Glanzman DL. 1994. Hebbian induction of long-term potentiation of Aplysia sensorimotor synapses: partial requirement for activation of an NMDA-related receptor. Proc Biol Sci 255: 215-221.

Malenka RC, Nicoll RA. 1999. Long-term potentiation--a decade of progress? Science 285: 1870-1874.

McBain CJ, Mayer ML. 1994. N-Methyl-D-aspartic acid receptor structure and function. Physiol Rev 74: 723-760.

Miyashita T, Oda Y, Horiuchi J, Yin JCP, Morimoto T, Saitoe M. 2012. $\mathrm{Mg}(2+)$ block of Drosophila NMDA receptors is required for long-term memory formation and CREB-dependent gene expression. Neuron 74: $887-898$.

Moyano S, Frechilla D, Del Río J. 2004. NMDA receptor subunit and CaMKII changes in rat hippocampus induced by acute MDMA treatment: a mechanism for learning impairment. Psychopharmacology 173: $337-345$.

Mukherjee B, Morrison GL, Fontaine CJ, Hou Q, Harley CW, Yuan Q. 2014. Unlearning: NMDA receptor-mediated metaplasticity in the anterior piriform cortex following early odor preference training in rats. J Neurosci 34: 5143-5151.

Mukherjee B, Harley CW, Yuan Q. 2015. Learning-induced metaplasticity? Associative training for early odor preference learning down-regulates synapse-specific NMDA receptors via mGluR and calcineurin activation. Cereb Cortex doi: 10.1093/cercor/bhv256.

Müssig L, Richlitzki A, Rössler R, Eisenhardt D, Menzel R, Leboulle G. 2010. Acute disruption of the NMDA receptor subunit NR1 in the honeybee brain selectively impairs memory formation. J Neurosci 30: 7817-7825.

Pedreira ME, Pérez-Cuesta LM, Maldonado H. 2002. Reactivation and reconsolidation of Long-term memory in the crab Chasmagnathus: protein synthesis requirement and mediation by NMDA-type glutamatergic receptors. J Neurosci 22: 8305-8311.

Pérez-Cuesta LM, Hepp Y, Pedreira ME, Maldonado H. 2007. Memory is not extinguished along with CS presentation but within a few seconds after CS-offset. Learn Mem 14: 101-108.

Petralia RS, Yokotani N, Wenthold RJ. 1994. Light and electron microscope distribution of the NMDA receptor subunit NMDAR1 in the rat nervous system using a selective anti-peptide antibody. J Neurosci Nurs 14: $667-696$. 
Rao A, Craig AM. 1997. Activity regulates the synaptic localization of the NMDA receptor in hippocampal neurons. Neuron 19: 801-812.

Riedel G, Platt B, Micheau J. 2003. Glutamate receptor function in learning and memory. Behav Brain Res 140: 1-47.

Roberts AC, Glanzman DL. 2003. Learning in Aplysia: looking at synaptic plasticity from both sides. Trends Neurosci 26: 662-670

Romano A, Lozada M, Maldonado H. 1990. Effect of naloxone pretreatment on habituation in the crab Chasmagnathus granulatus. Behav Neural Biol 53: 113-122.

Tano MC, Molina VA, Pedreira ME. 2013. The involvement of the GABAergic system in the formation and expression of the extinction memory in the crab Neohelice granulata. Eur I Neurosci 38: $3302-3313$.

Tovar KR, Westbrook GL. 2002. Mobile NMDA receptors at hippocampal synapses. Neuron 34: 255-264.
Troncoso J, Maldonado H. 2002. Two related forms of memory in the crab Chasmagnathus are differentially affected by NMDA receptor antagonists. Pharmacol Biochem Behav 72: 251-265.

Tsien JZ. 2000. Linking Hebb's coincidence-detection to memory formation. Curr Opin Neurobiol 10: 266-273.

Villmann C, Strutz N, Morth T, Hollmann M. 1999. Investigation by ion channel domain transplantation of rat glutamate receptor subunits, orphan receptors and a putative NMDA receptor subunit. Eur J Neurosci 11: $1765-1778$.

Wenthold RJ, Prybylowski K, Standley S, Sans N, Petralia RS. 2003. Trafficking of NMDA receptors. Annu Rev Pharmacol Toxicol 43: $335-358$.

Received January 16, 2016; accepted in revised form May 25, 2016. 


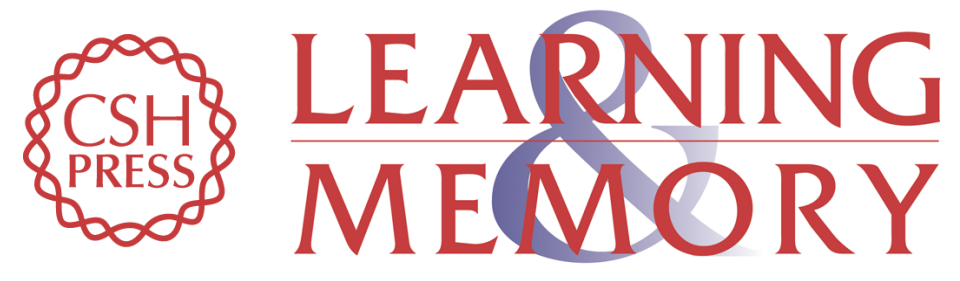

\section{Surface expression of NMDA receptor changes during memory consolidation in the crab Neohelice granulata}

Yanil Hepp, Angeles Salles, Martin Carbo-Tano, et al.

Learn. Mem. 2016, 23:

Access the most recent version at doi:10.1101//m.041707.116

References This article cites 37 articles, 9 of which can be accessed free at:

http://learnmem.cshlp.org/content/23/8/427.full.html\#ref-list-1

Creative This article is distributed exclusively by Cold Spring Harbor Laboratory Press for the

Commons

first 12 months after the full-issue publication date (see

License http://learnmem.cshlp.org/site/misc/terms.xhtml). After 12 months, it is available under a Creative Commons License (Attribution-NonCommercial 4.0 International), as described at http://creativecommons.org/licenses/by-nc/4.0/.

Email Alerting Receive free email alerts when new articles cite this article - sign up in the box at the Service top right corner of the article or click here. 